\title{
The Influence of Organizational Structure and Organization Culture on the Organizational Performance of Higher Educational Institutions: The Moderating Role of Strategy Communication
}

\author{
Haim Hilman ${ }^{1} \&$ Mohammed Siam ${ }^{1}$ \\ ${ }^{1}$ College of Business, University Utara Malaysia, Malaysia \\ Correspondence: Mohammed Siam, College of Business, University Utara Malaysia, Malaysia. E-mail: \\ mohpalestine@gmail.com
}

Received: April 10, 2014 Accepted: May 4, 2014 Online Published: June 25, 2014

doi:10.5539/ass.v10n13p142 URL: http://dx.doi.org/10.5539/ass.v10n13p142

\begin{abstract}
This paper examined the moderating of strategy communication, focusing on the influence of organizational structure and organizational culture on the performance of the higher educational Institutions in Palestine. The study generated a quantitative questionnaire data from 255 respondents representing the top, medium and low management level of the higher educational institutions in Palestine. Data were analyzed using the partial least squares-Structural equation model PLS-SEM. Overall, the findings revealed that organizational structure and organizational culture are significantly related to the performance of higher educational institutions in Palestine. A Further result of the moderating role showed that strategy communication failed to moderate the influence of both organizational structure and organizational culture on the organizational performance. Discussions on the findings, implication and limitation of the study were also provided.
\end{abstract}

Keywords: strategy execution, organizational structure, organizational culture, Strategy Communication, performance

\section{Introduction}

Obviously, the execution of strategy is not as clear and understood as the formulation of strategy. Thus, much more is known about planning rather than doing, about strategy making rather than making strategy work (Hrebiniak, 2005). Today, organizations work in a dynamic and complex environment that is continually changing. This has forced the organizations, including the higher education (HE) to revisit their strategic planning. The HE sector has begun to recognize that strategic planning is necessary for the maintenance of its own responsiveness to a rapidly changing environment (Rahimian, Polychronakis \& Sharp, 2009; Alashloo, Castka \& Sharp, 2005; Bryson, 2004; Streib \& Poister, 1990). Ostar (1989) claims that colleges and universities have experienced rapid changes associated with ageing facilities, changing technology, changing demographics, increasing competition, rising costs and funding cuts. Educational administrators are challenged to anticipate changes and formulate proactive responses that will enhance the educational processes within college and university campuses. However, there is an abundance of literature on different aspects of HE sector development (Rahemian, et al., 2009; Alashloo, et al., 2005). For instance, Hrebiniak (2005) identified four broad contextual factors that deserve special attention. These dimensions include the change of management context, the organisational culture context, the organisational power structure context and the leadership context. It was noted that these four dimensions are believed to affect each others. Even when these four factors are synchronized, the prognosis for effective strategy implementation is expected to be very positive.

Furthermore, the higher learning institutions are exceptional organizations in their structures and purposes and applying a suitable and strategic management is crucial because the management and activities held are different from those of industrial, productive or service organizations. In other words, universities are not unitary institutions. Faculties and schools have diverse tasks of preparing students for admission into specific professions, and inducting them into intellectual backgrounds and research methods according to the academic disciplines. Professions and disciplines have external reference groups, and in universities, staff loyalty can be strongly devoted to their professionalism or to the interactional disciplinary network as a whole rather than to the apparently less relevant university that employs them (Anderson, Johnson \& Milligan, 1999). The environment 
today has become increasingly uncertain and unpredictable for public and private universities. Hence, the leaders of these institutions must learn, think and act strategically (Bryson, 2004). In order to be able to control and adapt to the environmental changes, clear approach with long-range planning techniques should be used in the strategic management (Rahimnia, Polychronakis, \& Sharp, 2009). Although this issue has been there, yet only few studies focus their attention on the importance of strategic communication and how it influences organizational performance (Maas, 2008). As pointed out by Forman and Argenti (2005), although an entire discipline is devoted to the study of organizational strategy as well as strategy execution, however, little attention is extended to the link between communication and strategy.

Studies on strategy execution (including organizational structure and organizational culture) and performance are presumed to be abundant, where several authors have significantly contributed in this area (Wilden, Gudergan, Nielsen and Lings, 2013; Alamsjah, 2011; Pucko and Cater, 2010; Mieso, 2010; Rahimnia, et al, 2009; Li, Guohui \& Eppler, 2008; Hrebiniak, 2008; Neilson, Martin \& Power, 2008; Malik, 2007; Malik, 2007; Higgins, 2006; Okumas, 2003). These authors (e.g. Rahiminia, Polychronakis, \& Sharp, 2009; Brenes, Mena, Molina 2008; Delisi, 2006; Hrebiniak, 2006; Alashloo, Castka, \& Sharp, 2005; Raps, 2004; Okumas, 2003. 2001; Alton and Ikavako, 2002; Al-Mishari \& Zairi, 1999; Al-Gamdi, 1998), who examined the organizational structure and organizational culture, noted that these two dimensions of strategy execution are very important in determining the success or failure of organizational performance. However, one major weakness of these studies is the inability to integrate both organizational structure and organizational culture into a single framework that affects organizational performance.

In a study conducted by Fernandez \& Rainey (2006), they noted that related factors such as the organizational structure and organizational culture are the most effective strategy execution factors that affect organizational performance. They suggested that further studies in this area should moderate the relationship between organizational structure and organizational culture and the organizational performance with strategy communication. Accordingly, a study by Andrew, Boyne, Law and Walker (2011) equally recommended that strategy communication should be utilized as a moderator testing for the influence of organizational structure and organizational culture on the organizational performance. Based on this, the present study intends to examine the moderating role of strategy communication on the influence of organizational structure and organizational culture on the organizational performance with particular focus on the Higher Education Institutions in Palestine.

\section{Literature Review}

\subsection{Organizational Structure (OS)}

The structure of an organization is typically defined as "the sum total of the ways in which it divides its labor into distinct tasks and then achieves coordination among them" (Mintzberg, 1979, p. 2; Wilden, Gudergan, Nielsen \& Lings, 2013). The theoretical literature by Slater et al. (2010) argues that a different organizational structure is required to take decisions and to coordinate the work based on the strategy type, a different decision orientation is needed (e.g. Effectiveness versus efficiency). They added that the organizational structure is typically defined by three constructs, namely formalization or the degree to which decisions and working relationships are governed by formal rules and procedures, centralization or the degree to which decision authority is closely held by top managers or is delegated to middle and lower level managers, and specialization or the extent to which the organization employs experts or generalists

Moreover, structures can be classified using a mechanistic-to-organic structural dimension. Mechanistic structures are characterized by centralized decision-making, adherence to formal rules and procedures, tight control of information flows and elaborate reporting structures. In contrast, organic structures are typically associated with de-centralized decision-making, open communication, organizational adaptiveness, and de-emphasis on formal rules and procedures (Burns \& Stalker, 1961; Lawrence \& Lorsch, 1967; Malik \& Mahmood, 2012; Wilden, Gudergan, Nielsen, \& Lings, 2013).

Previous studies have established the relationship between strategy execution organizational level dimensions and organizational performance. For instance, the link between different systems and people in an organization to ensure the effective execution strategy is defined by the organizational structure. Noble (1999) observed that many studies have been carried out which investigated the associations between structure and strategy formulation. However, studies conducted on the relationship between structure and execution of strategy is perceived to be few. Further, Noble (1999) showed that structure seems to have an effect on how strategy is executed. This is buttressed by his claim that "a proper strategy-structure alignment is a necessary precursor to the successful execution of new business strategies" (Noble, 1999). Skivington and Daft (1991) analyzed the 
structural aspect of implementation from the angle of modality framework. This framework consists of structure and systems and its concept is described as "the framework aspect of organization structure includes rules, prescriptions of authority, division of labor, and hierarchy of authority" (1991). On the other hand, Maas, (2008), Olson, Slater \& Hult (2005) claimed that organizational structure dimensions are decentralization and formalization which could have a significant influence on the organizational performance.

According to a study by Heide, Grønhaug and Johannessen"s (2002), factors associated to the organizational structure are seen as the second essential implementation obstacle. Accordingly, Drazin and Howard (1984) perceived an effective strategy-structure alignment as an important precursor for an effective implementation of new business strategies. Both authors observed that a competitive environmental shift would force a change in the organizational structure. For instance, if firms fail to realign, they may experience poor performance that would put them at a competitive disadvantage. Furthermore, Gupta (1987) found that decentralized structures tend to generate higher levels of SBU success irrespective of the context of the strategy. In a similar dimension, Schaap (2006) affirmed that an effective strategic adjustment is correlated with a successful strategy implementation. Thus, the type of strategy adopted by the firm may warrant different conditions based on the organizational structure. White (1986) noted that the fit between business unit strategy and the internal organization of multi-business companies could affect business unit performance. In other words, it is perceived that business unit specific strategy on cost would produce a better ROI with a low autonomy.

Furthermore, the cost strategy of ROI is relatively better when their functional responsibilities shared among them. A study by Olson, Slater and Hult (2005) produced a classification of responsibilities that grouped structure/behavior types into four, namely management dominant, customer-centric innovators, customer-centric cost controllers and the middle ground. These grouping of structures/behavior into types should be aligned with a particular business strategy such as prospectuses, analyzers, low cost defenders and differentiated defenders with a view to understand the combination(s) of structures and behavior that best suit and aid the implementation process for a particular strategy.

\subsection{Organizational Culture (OC)}

In the context of a group, culture has to do with people's interaction, interaction between ideas and behaviors. Dobni (2003) defines culture as "the collective thoughts and actions of employees that manifest the strategic orientation of the firm. Culture drives strategy and it is an internal variable that the firm can control". Two important elements are emphasized within the definition, namely 1) the organization culture shows their strategic orientation and approach to the execution of strategy and 2) culture is considered a variable which is under the control of an organization and the organization can alter its present culture if it is not desirable (Baily, 2008). Organisational culture refers to the shared values, attitudes and norms of behavior that create the propensity for individuals in an organization to act in certain ways. However, one of the most common culture-related problems in companies is a lack of trust (Hrebiniak, 2005), which usually results in poor or inadequate information and knowledge sharing between individuals and/or business units responsible for strategy implementation. This problem was, for example, ranked as one of the largest obstacles to strategy execution by American managers (Cater \& Puko, 2010; Maas, 2008; Hrebiniak, 2005). Another common cultural problem is the domination of the short-term orientation in a company. For instance, the two independent studies conducted by Alexander (1985) and Al-Ghamdi (1998) report that competing short-term activities distract attention from strategy implementation in $64 \%$ and $83 \%$ of companies, respectively (Cater \& Puko, 2010). Also, a study by Alashloo, et al., (2005) in Iran on the same issue found that a strong relationship between "lack of adequate communication" and "lack of understanding of strategy by academic staff". The result was attributed to the social and cultural attitudes among senior managers in the country. In Iran, for instance, it was observed that the cultural practice is as such that all the information about planning, such as mission, goal and even strategy, is typically not disclosed to other parties and kept in elite groups only. This suggests that a close link to the "incompatible organisational culture" and "lack of adequate organisational support". Similarly, the study of the Indonesian organizations by Alamsjah (2011) identified a number of issues related to the top five key success factors. Among these issues is the corporate culture which is seen as the enabler or catalyst for successful strategy implementation. For instance, it is believed that the more conducive the culture is, the more aggressive the middle managers are. The study classified cultural values as innovation, action orientation, results orientation, team orientation, information sharing, and openness to constructive criticism.

Additionally, the integrative strategy implementation by Maas (2008) states that changing the culture of an organization is neither easy nor fast. Moreover, it may represent an obstruction to effective execution. Further, the behavior and emotion of fear (culture of non-trust), which stem from it, are important as they can bring both positive as well as negative effects to the organizational culture and execution performance. He further states that 
members of an organization have certain fears in their career life, such as losing the job, taking high responsibility, which is called "culture of fear". He mentioned firstly fear to offend others, then fear in job security, fear of making mistakes and taking initiatives, fear of responsibility, fear of participating, and fear of change. Many researchers focused on the phenomenon of resistance to change which is defined as any conduct that serves to maintain the status quo in the face of pressure to alter the status quo. Reid (1989) claims that organizational members with no exception of managers, and high ranked employees often feel distressed by the change, who would often resist it. Kotter and Schlesinger (1979) argue that the disturbance which accompanies organizational change usually shakes the company's stable interests and upsets the established routine (Noble, 1999).

\subsection{Organizational Performance $(O P)$}

Many organizations try to develop and adopt a variety of organizational performance measurement systems to monitor and drive their improvement of specified results and communicate their vision, goals, objectives, measures, aims, and outcomes to human resources and component in a coherent fashion. This system is the balance score card BSC (Brown, 2010).

The Balance Scorecard (BSC) is such a tool that provides a mix of financial and non-financial means to monitor and manage organizational performance. The Balanced Scorecard developed by Kaplan and Norton $(1996,1992)$ emerged as a method to explicate organizational performance and to have a clear and traceable means to manage it, based on four perspectives, which are financial, internal, customer and learning and growth.

The financial perspective provides a combination of both traditional accounting measures and identification of leading financial indicators of future performance. The internal process focuses on metrics that reveal internal operating performance. The customer measures often focus on satisfaction, loyalty and profitability to ensure that the right customers are receiving the right response. The learning and growth perspective focuses on how well-learning and knowledge are managed and cultivated to support strategic goals (Fuentes, 2008).

\subsubsection{The Organizational Structure and Organizational Performance}

The organizational structure was indicated by many studies, and currently the execution research requires extra investigation about the role of organizational structure in the strategy execution process. Cater and Pucko (2010) recommended that there was a relationship between the good organizational structure and organizational performance in Slovenia; therefore, they recommended that further studies should involve it in other sectors, such as the education sector. Rahimian, et al. (2009) and Alashloo, et al, (2005), in their studies on the higher education sector in Iran, have linked between the organizational structure and organizational culture and considered them as success factors having a positive impact on the organizational performance.

\subsubsection{The Relationship between Organizational Culture and Organizational Performance}

The strategy execution literature up to the present has been studying the organizational culture and its effect on performance. Many studies have investigated the role of organizational culture in the organization, and most of these studies indicate a significant role in the organization. These studies recommended more studies to be done on strategy execution and culture in many sectors, especially in the education sector (Almsajah, 2011; Cater \& Pucko, 2010; Rahimnia, et al, 2009; Tolleson, 2009; Hrebiniak \& Macllaster, 2004).

Maas (2008) found different dimensions of the organizational culture, specifically the widely researcher's talk about the culture of fear and how it affects the performance in the organizations. Delisi (2006) points out that the organizational culture can sabotage the strategy execution process and affect the performance if it is not considered.

2.3.3 The Relationship between Strategy Communication and Organizational Structure and Organizational Culture

Forman and Argenti (2002) also note that strategy communication researchers have become increasingly interested in the contribution of communication to a company's ability in creating and disseminating its strategy in the last decade. However, very few authors have investigated the link between communication and strategy execution, focusing primarily on how corporate communication affects the business relationship with its various stakeholders. Numerous researchers have already emphasized the importance of communication in the process of strategy execution (Alexander, 1985; Rapert \& Wren, 1998; Peng \& Litteljohn, 2001; Heide, Grønhaug \& Johannessen, 2002; Tourish, 2005; Schaap, 2006, Li, Guohui \& Eppler, 2008). The study by Alashloo, et al., (2005) on the higher educational institutions in Iran also found "incompatible organisational culture" and "lack of adequate communication" as the most important organisational impeders as mentioned by the respondents. Similar findings were also reported by Alexander (1991), Al-Ghamdi (1998), Noble (1999), Aaltonen and 
Ikavaiko (2002), Okumus (2001) and Dobni (2003), which noted that "incompatible organisational culture" and "lack of adequate communication" are also organisational impeders. The findings by Peng and Litteljohn (2001) show that effective communication is a key requirement for effective strategy execution. Strategy communication plays an important role in training, knowledge dissemination and learning during the process of strategy execution. In fact, communication is pervasive in every aspect of strategy execution as it relates in a complex way to organize processes, organizational context and implementation objectives which, in turn, have an effect on the process of implementation.

Strategy communication hindrances account for more regularly than other types of obstructions, for example, organizational structure boundaries, administration difficulties, or share values (culture) barriers. Heide, Grønhaug and Johannessen"s (2002), for instance, demonstrate different types of strategy communication issues (without pointing out what they are). These communication issues may be impacted to some degree by the organizational (hierarchical) structure. As stated by Heide, Grønhaug and Johannessen, they constitute the key boundary to the execution of planned strategic events. Rapert, Velliquette and Garretson (2002) state that strategy communication and organizational culture play a paramount part in the execution process. Specifically, when vertical communication is regular and frequent, strategic consensus (shared understanding about strategic necessities) is upgraded and the organizational performance will improve. They investigate vertical communication linkages as a means by which key agreement and execution could be improved (Li, Guohui \& Eppler, 2008).

\subsection{Theoretical Underpinning}

Bertalanffy (1968) introduced the general system theory and mentioned that each element in the system is interrelated with each other as such changing an element would cause other elements to change. In this case, the reward system has been studied by many researchers and its role accompanied with the organizational structure and organizational culture is to get a high level of organizational performance. Thus, the organizational structure and organizational culture are embedded in the general system theory (Bertalanffy, 1968). The contingency theory also embeds both the organizational structure and organizational culture because it is studied in a turbulent environment such as in Palestine, Gaza (Lawrence and Lorch, 1967; Burrell and Morgan, 1979). Thus, these theories are very relevant to the present study as they help explain their relevancy in the explanation of the organizational structure and organizational culture and how they affect organizational performances (Slater, et al., 2010; Barney, 1995).

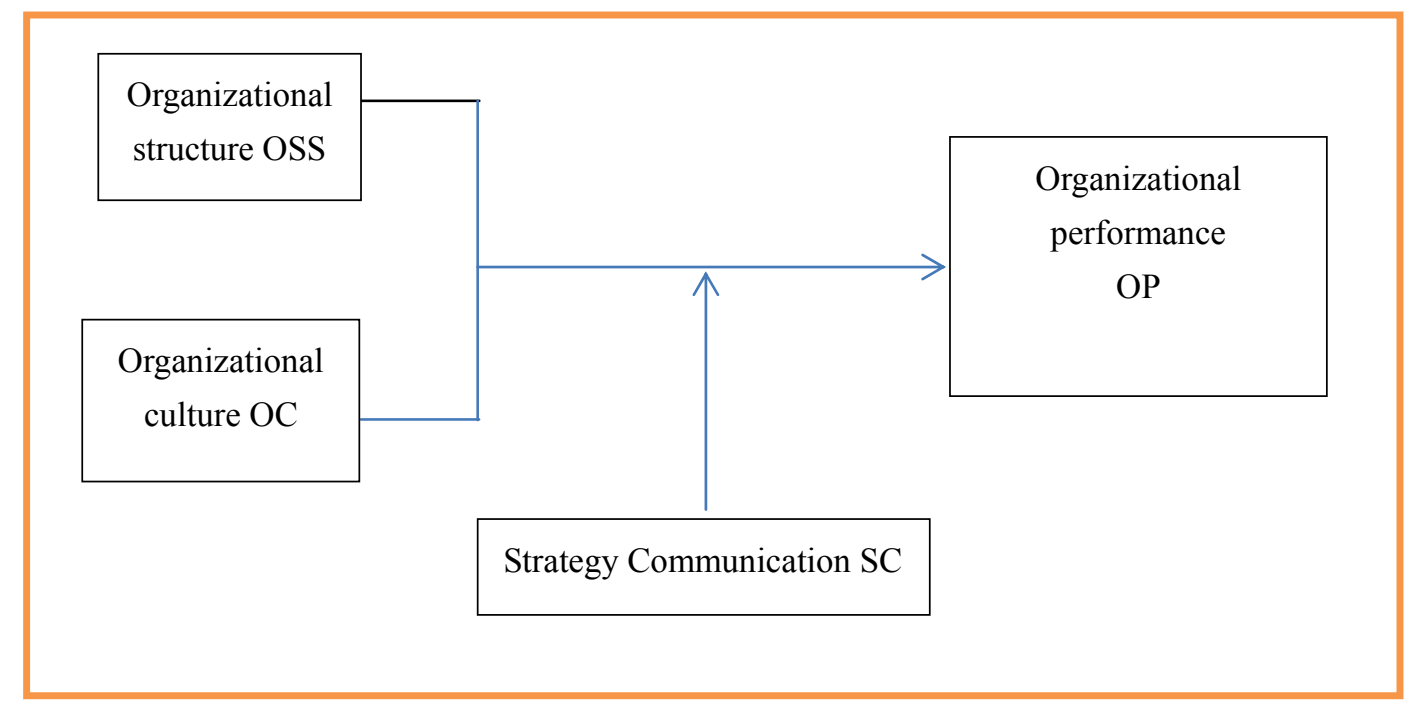

Figure 1. The Study Framework

\subsection{Hypothesis Development}

Based on the literature review and also in line with the conceptual framework, the study formulates the following hypotheses:

$\left.\mathbf{H}_{1}\right)$ There is a relationship between organizational structure and the organizational performance.

$\mathbf{H}_{2}$ ) There is a relationship between organizational culture and the organizational performance. 
$\mathbf{H}_{3}$ ) Communication moderates the relationship between organizational structure and the organizational performance.

$\mathbf{H}_{4}$ ) Communication moderates the relationship between organizational culture and the organizational performance.

Table 1. Convergent Validity Analysis

\begin{tabular}{|c|c|c|c|c|c|}
\hline Construct & Items & Loadings & $\begin{array}{c}\text { Cronbach's } \\
\text { Alpha } \\
\end{array}$ & CR & AVE \\
\hline \multirow[t]{7}{*}{ OSS } & a10 & 0.515 & 0.713 & 0.802 & 0.500 \\
\hline & a3 & 0.519 & & & \\
\hline & a5 & 0.657 & & & \\
\hline & a6 & 0.677 & & & \\
\hline & a7 & 0.724 & & & \\
\hline & a8 & 0.540 & & & \\
\hline & a9 & 0.591 & & & \\
\hline \multirow[t]{25}{*}{$\mathrm{OC}$} & b10 & 0.551 & 0.902 & 0.914 & 0.500 \\
\hline & b11 & 0.561 & & & \\
\hline & b12 & 0.604 & & & \\
\hline & b13 & 0.531 & & & \\
\hline & b14 & 0.531 & & & \\
\hline & b15 & 0.595 & & & \\
\hline & b16 & 0.641 & & & \\
\hline & b17 & 0.643 & & & \\
\hline & b18 & 0.675 & & & \\
\hline & b19 & 0.563 & & & \\
\hline & b2 & 0.450 & & & \\
\hline & b20 & 0.486 & & & \\
\hline & b21 & 0.539 & & & \\
\hline & b22 & 0.574 & & & \\
\hline & b23 & 0.419 & & & \\
\hline & b24 & 0.483 & & & \\
\hline & b25 & 0.538 & & & \\
\hline & b26 & 0.584 & & & \\
\hline & b27 & 0.568 & & & \\
\hline & b28 & 0.562 & & & \\
\hline & b4 & 0.327 & & & \\
\hline & b5 & 0.519 & & & \\
\hline & b7 & 0.601 & & & \\
\hline & b8 & 0.586 & & & \\
\hline & b9 & 0.606 & & & \\
\hline
\end{tabular}

a: $\mathrm{CR}=(\Sigma$ factor loading $) 2 /\{(\Sigma$ factor loading $) 2)+\Sigma$ (variance of error $)\}$

b: AVE $=\Sigma$ (factor loading $) 2 /(\Sigma$ (factor loading $) 2+\Sigma$ (variance of error $)\}$ 


\section{Methodology}

\subsection{Research Design}

The study applied a cross-sectional research design technique with a quantitative research approach of survey questionnaires. Hair, Black, Babin, Anderson and Tatham (2006) affirmed that both cross-sectional design and quantitative research approach of survey questionnaire are suitable in a social science study like the current one. Further, it is faster and easier in terms of gathering information within a limited time.

\subsection{Population and the Sample Technique}

A simple random sampling technique was adopted to select 13 higher learning institutes from Gaza, Palestine. These institutions were identified through the directory of the Ministry of Higher Education of Palestine. In all, there are only 13 higher learning institutions that are currently registered under the Ministry of Higher Education of Palestine.

\subsection{Unit of Analysis}

The unit of analysis for this study is an organization (higher education institutions). It includes all individual organizations in the higher education sector in Palestine, particularly those that are currently registered under the Palestinian higher education authority.

\subsection{Research Instrumentation and Measurement}

First and foremost, all the items were measured through the seven-point Likert scale of $1=$ strongly disagree to $7=$ strongly agree. Second, the variables were measured according to what they reflect. For the organizational culture, it was measured using twenty-five (25) items adapted from Maas (2008) reflecting fear, while organizational structure was measured using nine (9) items adapted from Maas (2008) and reflected for the organizational performance, and 22 items consist of the four perspectives of balance scorecard from Franklin (2011).

\section{Data Collection Procedure}

The data collection procedure for this study is self-administered. All the 255 questionnaires for this study were distributed and retrieved through self-administration, which is also called drop-off and pick procedure. Both the questionnaire distribution and its retrieving were done by the researcher.

\subsection{The Convergent Validity}

This was used to determine the degree to which the measured constructs correlate positively with a measure of the same construct (Hair, Hult, Ringle and Sarstedt, 2014). It measured the correlation between the formative and reflective constructs. The convergent validity is also determined by examining the loadings, the composite reliability and the average variance extracted. In this case, items that are high load factor of 0.7 and with the average variance extracted (AVE) of at least 0.5 and the composite reliability of 0.7 are all considered acceptable. Table 1 depicts the loadings, reliability (Cronbach's Alpha) and the AVE for this study. It indicates that all the items met the acceptable limits as suggested by Hair, Hult, Ringle and Sarstedt (2014), Bagozzi and Yi (1988). The results in Table 1 show that the measurement model has an appropriate convergent validity as suggested by Bagozzi \& Yi (1988).

Table 2. The Discriminant Validity Analysis

\begin{tabular}{cllccccc}
\hline Construct & CP & CS & F & IN & LG & OC & OSS \\
\hline CP & $\mathbf{0 . 7 8 3}$ & & & & & & \\
CS & 0.657 & $\mathbf{0 . 7 6 6}$ & & & & & \\
F & 0.469 & 0.451 & $\mathbf{0 . 7 6 8}$ & & & & \\
IN & 0.744 & 0.733 & $\mathbf{0 . 5 1 8}$ & $\mathbf{0 . 7 9 0}$ & & & \\
LG & 0.540 & 0.531 & $\mathbf{0 . 4 8 9}$ & 0.545 & $\mathbf{0 . 7 3}$ & & \\
& & & & & $\mathbf{1}$ & & \\
OC & 0.207 & 0.316 & $\mathbf{0 . 3 2 1}$ & 0.214 & 0.21 & $\mathbf{0 . 7 0 7}$ & \\
& & & & & 0 & & \\
OSS & 0.117 & 0.146 & $\mathbf{0 . 1 1 3}$ & 0.114 & 0.16 & 0.622 & $\mathbf{0 . 7 0 7}$ \\
& & & & & 5 & & \\
\hline
\end{tabular}




\subsection{The Discriminant Validity Analysis}

The discriminant validity was used to measure the degree to which the group of items was able to distinguish the constructs from other constructs in the model as suggested by Fornell and Larcker (1981). By doing this, it was expected that the items of each construct should indicate a variance greater than that shared with other constructs (Compeau et al., 1999). Normally, the discriminant validity is confirmed and assumed if the values of the diagonal elements are higher than other values in their respective rows and columns. Table 2 demonstrates the detailed results of the discriminant validity, including the correlation among variables.

\subsection{The Structural Model, Inner Model and Hypothesis Testing}

This was used in the current study to test the proposed hypotheses in order to establish the relationship between the endogenous and exogenous variables. It was done by running the bootstrapping in Smart PLS 2.0. Figure 2 and Table 3 below depict the results.

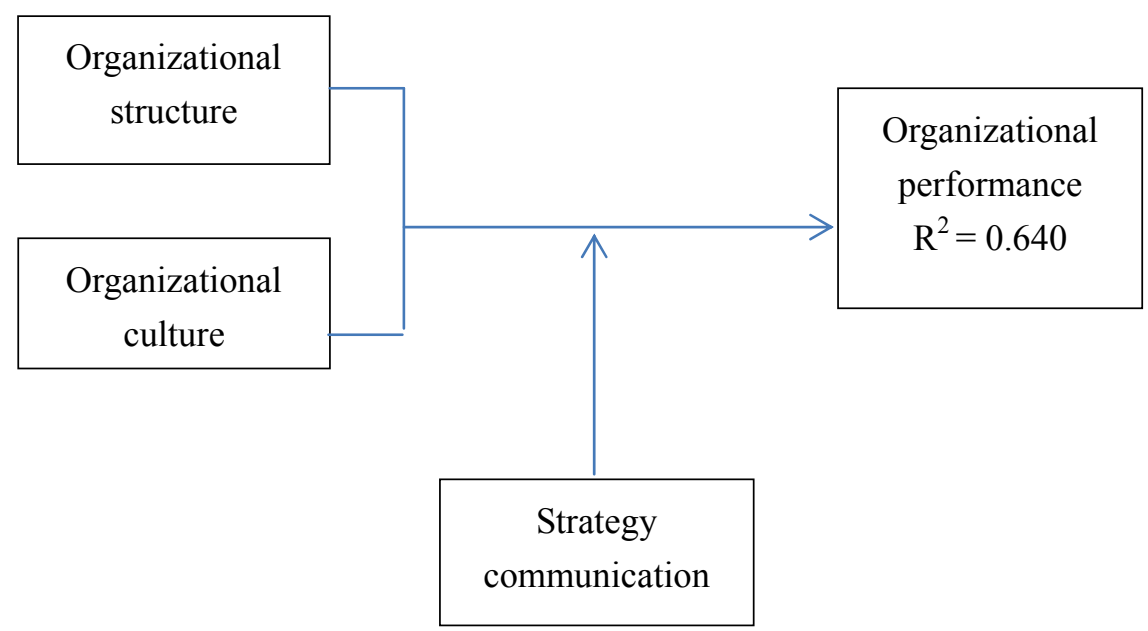

Figure 2. The direct relationship between the independent variables (organizational structure - organizational culture and Strategy communication) and the dependent variable (organizational performance)

Table 3. The Results of the Inner Structural Model

\begin{tabular}{|c|c|c|c|c|c|c|}
\hline Hypothesis & Hypothesized Path & $\begin{array}{c}\text { Path } \\
\text { Coefficient }\end{array}$ & $\begin{array}{c}\text { Standard } \\
\text { Error } \\
\end{array}$ & T value & $P$ value & Decision \\
\hline $\mathrm{H}_{1}$ & $\mathrm{OC}->\mathrm{OP}$ & 0.066 & 0.056 & 1.175 & 0.120 & $\begin{array}{c}\text { Not } \\
\text { Supported }\end{array}$ \\
\hline $\mathrm{H}_{2}$ & OSS -> OP & 0.024 & 0.054 & 0.447 & 0.327 & $\begin{array}{c}\text { Not } \\
\text { Supported }\end{array}$ \\
\hline $\mathrm{H}_{3 b}$ & OSS * CS -> OP & -0.050 & 0.070 & 0.717 & 0.237 & $\begin{array}{c}\text { Not } \\
\text { Supported }\end{array}$ \\
\hline $\mathrm{H}_{4}$ & $\mathrm{OC} * \mathrm{CS}->\mathrm{OP}$ & $(-) 0.160 * *$ & 0.067 & 2.382 & 0.009 & Supported \\
\hline
\end{tabular}

From Figure 2 and Table 3, it is revealed that OC has a negative and insignificant effect on the OP at the 0.1 level of significance $(\beta=0.066, t=1.175, \mathrm{p}<0.1)$. The result further revealed that OSS has insignificant effect on 
the organizational performance at the 0.1 level of significance $(\beta=0.024, t=447, p<0.1)$. Similarly, the OSS $*$ CS also has an insignificant and a negative effect on the organizational performance at the 0.1 level of significance $(\beta=0.050, t=717, p<0.1)$. The $\mathrm{Oc}^{*} \mathrm{CS}$ also has an insignificant effect on the organizational performance at the 0.1 level of significance $(\beta=0.160, t=2.382, p<0.05)$. Thus, the hypotheses $\left(\mathrm{H}_{1}, \mathrm{H}_{2}, \mathrm{H}_{3}\right.$ and $\left.\mathrm{H}_{4}\right)$ for this study are not supported.

\subsection{Predictive Relevance of the Model}

$\mathrm{R}^{2}$ and Cross-validated redundancy was utilized to examine the predictive power of the model. $\mathrm{R}^{2}$ refers to the variance in the endogenous variables that is explained by the exogenous variables. Table 4 revealed the $R_{2}$ represents $40.3 \%$ of the Organizational Performance that was explained by the organizational structure. Accordingly, $40.3 \%$ of the Organizational Performance was accounted for by the organizational culture. In line with the findings of this study, Cohen (1988) suggested a value of $\mathrm{R}^{2}$, where 0.26 is substantial, 0.13 is moderate and 0.02 is weak. Therefore, both $\mathrm{R}^{2}$ values for this study are considered substantial and the power of variables contained in the model to explain the organizational performance.

Furthermore, the study also used the $\mathrm{R}^{2}$, the Cross-Validated Redundancy values, to assess the quality of the model. This was done by conducting the Blindfolding procedures, where these values in Smart PLS were applied with a view to generate the cross-validated redundancy and cross-validated communality. To do this, the study removed sum of the values in the data which was later estimated as a missing value. After that, the estimated parameters are used to re- estimate the missing data and a comparison of the output was conducted. Table 4 provides the detailed results on the output as the cross-validated redundancy.

\begin{tabular}{|c|c|c|c|}
\hline Construct & R square & Cross Validated Redundancy & Cross Validated Communality \\
\hline Organizational Performance & 0.403 & 0.256 & 0.640 \\
\hline Organizational Structure & & & 0.933 \\
\hline Organizational Culture & & & 0.620 \\
\hline
\end{tabular}

According to Fornell and Cha (1994), the model under investigation will have the predictive quality if the cross-redundancy values were more than zero. Otherwise, the predictive quality of the model cannot be confirmed. Table 4 showed the obtained cross validated redundancy of 0.25 for OP. Therefore, these results confirmed that the model has adequate prediction quality.

\section{Discussion of Findings}

The study aims to examine the moderating role of strategy communication on the influence of strategy execution organization on the organizational performance. The study specifically investigated how strategy communication moderates the influence of strategy execution organization dimensions, namely organizational structure and organizational culture on the organizational performance with specific focus on higher education institutions in Palestine. The study applied the structural equation modeling, particularly Partial Least Square with SmartPLS analysis technique for the data analysis.

Overall, the findings revealed that organizational structure and organizational culture are not significantly related to the performance of higher education institutions in Palestine. First, the results demonstrate a significant relationship between the organizational culture and organizational performance. Thus, the study failed to support the hypothesis that the organizational culture will influence the organizational performance. This finding is at variance with Rahimnia, Polychronakis \& Sharp (2009), Maas (2008), Balzarov, Balzrova, Bamber, McCambridge \& Sharp (2004) and Swanson and Power (2001) who affirmed that organizational culture- culture of fear or (Culture of non-trust) is a critical and significant factor that determines the success or failure of any organization including those educational institutions in Palestine.

Secondly, the result also failed to reveal a significant relationship between the organizational structure and organizational performance. Our findings failed to affirm the hypothesis that organizational structure will influence the organizational performance. This finding is at variance with previous studies' findings (Cater \& Puko, 2010; Rahimnia, Polychronakis, \& Sharp, 2009; Maas, 2008; Balzarov, Balzrova, Bamber, McCambridge, \& Sharp, 2004; Swanson \& Power, 2001), which affirmed that organizational structure is a critical and significant factor that determines the success or failure of any organization including those educational institutions in Palestine. One plausible explanation for this result could be due to the vagueness and misunderstanding among staff during the strategy execution efforts due to the execution activities and procedures, and because the responsibilities were not formalized and this will make the employees do not know what they can do or cannot. It could also be due to the authoritarian management there, where the staff do not 
engage in the formulation of study. Automatically, this will affect the strategy execution efforts even though this will require a close supervision of the staff of the management because staff will not be willing to take initiatives or be responsible for successful strategy execution activities and the competent employees will get frustrated.

For the moderating effect of strategic communication, further finding revealed that neither the influence of organizational structure nor organizational culture on the organizational performance is moderated by strategic communication. Our result indicates that strategic communication did not further explain the influence of both the strategy execution organization on the organizational performance. It suggests that strategy communication failed to strengthen the relationship between organizational structure and organizational performance and also the relationship between nor organizational culture and organizational performance. It shows that the moderating variable, strategy communication, failed to interact with the independent variables (organizational structure and organizational culture) to influence the dependent variable-organizational performance. In other words, strategy communication might be relevant in the further explanation of the relationship between organizational structure and organizational performance and also the relationship between nor organizational culture and organizational performance. However, we advise that our results should be interpreted with caution as strategic communication could be significant in other research environments. All in all, our findings to the moderating effect demonstrate the failure to affect the strength and the direction of the associations between organizational structure and organizational performance; and also the relationship between nor organizational culture and organizational performance. One key limitation of this study might be the quantitative nature of our data. Therefore, other research approaches such as qualitative and meta-analysis approach could be helpful in this regard. The use of these approaches may possibly produce additional insight in the moderating role of strategy communication.

\section{References}

Alamsjah, F. (2011). Key Success Factors in Implementing Strategy: Middle-Level Managers' Perspectives. Procedia Social and Behavioral Sciences, 24, 1444-1450.

Alashloo, F. R., Castka, P., \& Sharp, J. M. (2005). Toward Understanding the Impeders of Strategy Implementation in Higher Education (HE) A Case of HE institutes in Iran. Quality Assurance in Education, 13(2), 132-147.

Alexander, L. D. (1985). Successfully implementing strategic decisions. Long Range Planning, 18(3), 91-7.

Alexander, L. D. (1991). Strategy Implementation: Nature of the problem. In D. E. Hussey (Ed.), International Review of Strategic Management, 2(1).

Al-Gamdi, S. M. (1998). Obstacles to Successful Implementation of Strategic Decisions. The British Experience. European Business Review, 6, 322-327.

Al-Gamdi, S. M. (2006). Obstacles to Successful Implementation of Strategic Decision: The Saudi Case. King Fahed University of Petroleum \& Minerals for the Development, the SABIC grant.

Allio, M. K. (2005). A short, practical guide to implementing strategy. The Journal of Business Strategy, 26(4), $12-21$.

Al-Mashari, M., \& Zairi, M. (1999). BPR Implementation Process: An Analysis of Key Success and Failure Factors. Business Process Management, 5(1), 87-112.

Anderson, D., Johnson, R., \& Millligan, B. (1999). Strategic Planning in Australia Universities. Canberra: Evaluations and Investigations Program Higher Education Division.

Bagozzi, R. P., Youjae, Y., \& Phillips, L. W. (1991). Assessing Construct Validity in Organizational Research. Administrative Science Quarterly, 36, 421-458. http://dx.doi.org/10.2307/2393203

Baily, O. L., (2008). Implementation of Strategic Planning in Church Ministry. USA: ProQuest LLC.

Balzrova, M. A., Bamber, C. J., McCambridge, S., \& Sharp, J. M. (2004). Key Success Factors in Implementation of Process-Based Management. A UK Housing Association Experience. Business Process Management Journal, 10(4), 387-399.

Beer, M., \& Eisenstat, R. A. (2000). The silent killers of strategy implementation and learning. Sloan Management Review, 41(4), 29-40.

Bhatti, O. K. (2011). Strategy Implementation: An Alternative Choice of 8S's. Annals of Management Research, $1(2), 52-59$.

Bossidy L., Charan, R., \& Burck, C. (2002). Execution: The discipline of getting things done. Crown Business: New York. 
Brenes, E. R., Mena, M., \& Molina, G. E. (2008). Key success factors for strategy implementation in Latin America. Journal of Business Research, 61(6), 590-598.

Bryson, J. M. (2004), Strategic Planning for Public and Non-profit Organisations: A Guide to Strengthening and Sustaining Organisational Achievement. San Francisco, CA: Jossey-Bass.

Cater, T., \& Pucko, D. (2010). Factors of Effective Strategy Implementation: Empirical Evidence from Slovenian Business Practice. JEEMS, 207-237.

Chin, W. W. (1995). The Partial Least Squares Approach to Structural Equation Modelling: Modern Methods for Business Research (pp. 295-336). Laurence Erlbaum Associates, Mahwah: Lawrence Erlbaum, 295-336.

Chin, W. W. (1998). In G. A. Marcoulides (Ed.), The partial least squares approach to structural equation modeling. New Jersey.

Connor, T. (2001). Product levels as an aid to functional strategy development. In Strategic Change, 10(4), 223-237.

Delisi, P. S. (2006). Strategy Execution: An Oxymoron or a Powerful Formula for Corporate Success? Organizational Synergies.

Dobni, B. (2003). Creating a Strategy Implementation Environment. Business Horizons, 46(2), 43-46.

Fornell C., \&Larcker, D. F. (1981). Evaluating structural equation models with unobservable variables and measurement error. Journal of Market Research, 18(1), 39-50.

Fornell, C., \& Cha, J. (1994). Partial least squares. In R. P. Bagozzi (Ed.), advanced methods of marketing research (pp. 52-78). Cambridge: Blackwell.

Fuentes, S. C. (2008). The Link between Learning Culture and Organizational Performance in Organizations using the Balance Scorecard. ProQuest LLC. USA.

Gottschalk, P. (2008). Organizational structure as predictor of intelligence strategy implementation in policing. International Journal of Law, Crime and Justice, 36(3), 184-195.

Govindarajan, V., \& Gupta, A. (1985). Linking control systems to business unit strategy: Impact on performance. Accounting, Organizations and Society, 10, 51-66.

Hair, J. F., Ringle, C. M., \& Sarstedt, M. (2011). PLS-SEM: Indeed a Silver Bullet. Journal of Marketing Theory and Practice, 19(2), 139-151. http://dx.doi.org/10.2753/MTP1069-6679190202

Hair, J., Black, B., Babin, B., Anderson, R., \& Tatham, R. (2006). Multivariate Data Analysis (6th ed.). Saddle River, NJ: Prentice-Hall.

Hair, J., Hult, G. T., Ringle, M. C., \& Sarstedt, M. (2014). A Primer on Partial Least Squares Structural Equation Modeling (PLS-SEM). SAGE Publications Inc.

Hambrick, D. C., \& Cannella, A. A. (1989). Strategy implementation as substance and selling. The Academy of Management Executive, 3(40), 278-285.

Hauc, A., \& Kova, J. (2000). Project management in strategy implementation: Experiences in Slovenia. International Journal of Project Management, 18(1), 61-67.

Higgins, J. M. (2005). The Eight 'S's of successful Strategy Execution. Journal of Change Management, 5(1), 3-13.

Hrebiniak, L. (2008). Making Strategy Work: Overcoming the Obstacles to Effective Execution. IVEY Business Journal.

Hrebiniak, L. G. (2005). Making strategy work: Leading effective execution and change. Upper Saddle River: Pearson Education.

Hrebiniak, L. G. (2006). Obstacles to Strategy Implementation. Organizational Dynamics, 35(1), 12-31.

Hrebiniak, L. G., \& Joyce, W. F. (1984). Implementing Strategy. Newyork. McMillan.

Hussy, D. E. (1996). The Implementation Challenge. Chichester: John Wiley, London.

Johnson, G., \& Scholes, K. (2002). Exploring Corporate Strategy. London: Prentice-Hall.

Kaplan, R. S., \& Norton, D. P. (1996a). The balanced scorecard: Translating strategy into action. Boston: Harvard Business School Press.

Kaplan, R. S., \& Norton, D. P. (1996b). Using the Balance Scorecard as a Strategic Management System. 
Harvard Business School Review, 74(1), 75-85.

Kaplan, R. S., \& Norton, D. P. (2005). The office of strategy management. Harvard Business Review, 83(10), $72-80$.

Kaplan, R. S., \& Norton, D. P. (2006). How to implement a new strategy without disrupting your organization. Harvard Business Review, 84(3), 100-109.

Kerr, J. (1985). Diversification strategies and managerial rewards: An empirical study. Academy of Management Journal, 28, 155-179.

Klein, K. L., \& Sorra, J. S. (1996). The challenge of innovation implementation. Academy of Management Review, 21(4), 22-42.

Mintzberg, H., \& Quinn, J. B. (1991). The Strategy Process: Concepts, Contexts, Cases (2nd ed.). Prentice-Hall, Upper Saddle River, NJ.

Napier, N. K., \& Smith, M. (1987). Product diversification, performance criteria and compensation at the corporate manager level. Strategic Management Journal, 8(2), 195-201.

Nayyar, M. J., \& Mahmood, R. (2012). Facilitating Corporate Entrepreneurship in Public Sector Higher Education Institutions: A Conceptual Model. Issues in Social and Environmental Accounting, 6(1/2), 26-49.

Neilson, G. I., Martin, K. L., \& Powers, E. (2007). The Secrets to Successful Strategy Execution. Harvard Business Review.

Noble, C. H. (1999). Building the Strategy Implementation network. Business Horizons, 42(6), 19-28.

Noble, C. H. (1999). The Eclectic Roots of Strategy Implementation Research. Journal of Business Research, 45, 119-134.

Okumas, F. (2002). Can Hospitality researches Contribute to the Strategic Management Literature?. Hospitality Management, 21, 105-110.

Okumas, F. (2003). Towards a Strategy Implementation Framework. Hospitality Management, 13(7), 327-338.

Okumus, F. (2001). Towards a strategy implementation framework. International Journal of Contemporary Hospitality Management, 13(7), 327-338.

Ostar, A. W. (1989). What the future holds for American colleges and universities. Vital Speeches, 55(18), 558-562.

Owen, A. A. (1982). How to implement strategy. Journal of Management Today, (July), 50-53.

Parnell, J. (2008). Strategy Execution in Emerging Economics: Assessing Strategic Diffusion in Mexico and Peru. Management Decision, 46(9), 1277-1298.

Rahimnia Alashloo, F., Castka, P., \& Sharp, J. M. (2005). Towards understanding the impeders of strategy implementation in higher education (HE): A case of HE institutes in Iran. Journal of Quality Assurance in Education, 13(2), 132-147.

Rajagopalan, N., \& Finkelstein, S. (1992). Effects of strategic orientation and environmental change on senior management reward system. Strategic Management Journal, (Special Issue 13), 127-142.

Rajagopalan, N. (1997). Strategic orientations, incentive plan adoptions, and firm performance: evidence from electric utility firms. Strategic Management Journal, 18(10), 761-785.

Rapert, M. I., Velliquette, A., \& Garretson, J. A. (2002). The strategic implementation process evoking strategic consensus through communication. Journal of Business Research.

Reed, R., \& Buckley, M. (1988). Strategy in action-techniques for implementing strategy.

Schaap, J. I., Stedham, Y., \& Yamamura, Y. H. (2008). Casino Management: Explore Jender-Based Differences in Perception of managerial Work. International Journal of Hospitality Management, 27, 87-97.

Sharma, P. N., \& Kim, K. H. (2012). A Comparison of PLS and ML Bootstrapping techniques in SEM: A Monte Carlo Study.

Slater, S. F., Olsen, E. M., \& Hult, G. T. (2010). Worried about Strategy Implementation?. Don't Overlook Marketing Role. Business Horizons, 53, 469-479.

Streib, G., \& Poister, T. (1990). Strategic planning in US cities. American Review of Public Administration, 20(1), 29-44. 
Tenenhaus, M., Esposito Vinzi, V., Chatelin, Y. -M., \& Lauro, C. (2005). PLS path modeling. Computational Statistics \& Data Analysis, 48(1), 159-205.

Wetzels, M., Odekerken-Schröder, G., \& Oppen, C. V. (2009). Using PLS path modeling for assessing hierarchical models: Guidelines and empirical illustration. MIS Quarterly, 33(1), 177-195.

Zhang, Y. (2009). A Study of Corporate Reputation's Influence on Customer Loyalty Based on PLS-SEM Model. International Business Research, 2(3), 28-35. http://dx.doi.org/10.4018/jebr.2006070103

\section{Copyrights}

Copyright for this article is retained by the author(s), with first publication rights granted to the journal.

This is an open-access article distributed under the terms and conditions of the Creative Commons Attribution license (http://creativecommons.org/licenses/by/3.0/). 